\title{
Significance of 2 dimensional-echocardiography in hypertensive disorders of pregnancy: a study in tertiary care centre, Ahmedabad, Western India
}

\author{
Purvi M. Parikh, Vishwa M. Goswami*, Sapana R. Shah, Rupa C. Vyas, Hiral Damor
}

Department of Obstetrics and Gynaecology, NHL MMC, Ahmedabad, Gujarat, India

Received: 02 November 2020

Accepted: 09 December 2020

\section{*Correspondence:}

Dr. Vishwa M. Goswami,

E-mail: vishwag61@gmail.com

Copyright: ( $)$ the author(s), publisher and licensee Medip Academy. This is an open-access article distributed under the terms of the Creative Commons Attribution Non-Commercial License, which permits unrestricted non-commercial use, distribution, and reproduction in any medium, provided the original work is properly cited.

\begin{abstract}
Background: Echocardiography is a safe, non-invasive technique to assess cardiac structure and function in pregnancy. Understanding the structure and function of the heart in hypertensive women is important in terms of timely diagnosis, better management and good prognosis. This study will focus on the importance and feasibility of Echocardiography as a routine investigation tool in hypertensive disorders of pregnancy.

Methods: This is a retrospective study of 150 cases of hypertension in pregnancy conducted at the Obstetrics and Gynaecology department of a tertiary care centre in the year June 2019-July 2020. Data was analysed in terms of complications seen in women who had structural and functional abnormalities in the echocardiographic scan in comparison to those hypertensive women who had a normal scan. The important Echocardiographic parameters were compared amongst cases of hypertension and their impact on fetomaternal outcome was discussed.

Results: In this study conducted amongst 150 pregnant women suffering from different forms of hypertensive disorders presenting in our institute for routine workup in the year 2019-2020, 12(8\%) had chronic hypertension, $75(50 \%)$ had gestational hypertension, whereas $63(42 \%)$ had pre- eclampsia. The incidence of structural valvular lesions in these categories as $2 \%, 3.34 \%$ and $4 \%$ respectively. Deranged echocardiographic parameters like decreased Left Ventricular Ejection Fraction in 10\%, decreased stroke volume in $28.6 \%$ and increased Left Ventricular mass in $26.6 \%$ are seen more in cases of pre-eclampsia compared to gestational hypertension and chronic hypertension.

Conclusions: Echocardiography is a valuable tool to stratify risk and can guide management in gestational hypertension, chronic hypertension and preeclampsia. Changes in cardiac function and morphology are recognizable at an asymptomatic early stage and correlate with disease severity and adverse outcomes. Preeclampsia has a greater impact on the heart than gestational hypertension, and changes are most pronounced in early onset, severe disease. Studying the cardiac structure and function in early trimesters can bring about better maternal and fetal outcome.
\end{abstract}

Keywords: Echocardiography, Hypertension, Left ventricular mass, Preeclampsia, Pregnancy

\section{INTRODUCTION}

Hypertensive disorders of pregnancy are one of the major contributors of maternal morbidity and mortality. It complicates $7.8 \%$ of all the pregnant women in India. ${ }^{1}$ Hypertensive disorders cause $10-15 \%$ of maternal deaths especially in the developing countries. ${ }^{2}$ It is the $2^{\text {nd }}$ most common cause of maternal mortality worldwide. ${ }^{3}$

Depending upon the gestational age of onset and presence of proteinuria, the hypertensive disorders are classified as gestational hypertension $(\mathrm{BP}>=140 / 90 \quad \mathrm{MM} \quad \mathrm{HG})$, 
preeclampsia (gestational hypertension and $>300 \mathrm{mg} / 24$ hrs proteinuria or signs of end organ damage), eclampsia (pre-eclampsia + seizures), chronic hypertension (gestational age of onset $<20$ weeks gestation) and Preeclampsia superimposed on chronic hypertension. ${ }^{4}$

Preeclampsia has a greater impact on the heart than Gestational Hypertension, and changes are most pronounced in early onset, severe disease. ${ }^{5}$ Studying the cardiac structure and function in early trimesters can bring about better maternal and fetal outcome.

Echocardiography is a safe, non-invasive technique to assess cardiac structure and function in pregnancy. ${ }^{6}$ Although operator dependent and requiring training to provide reproducible measurements, the temporal variability of echocardiography is small. ${ }^{7,8}$ Echocardiography in pregnancy with hypertension shows an increased left ventricular mass and remodelling causing diastolic dysfunction in some women. Several techniques have been used: two dimensional and $\mathrm{M}$ Mode Echocardiography, pulse Doppler analysis (PDA), tissue Doppler analysis and other newer techniques for better evaluation of chamber deformation. ${ }^{8}$

Pregnant women have an increased cardiac output accompanied with a decreased systemic vascular resistance. $^{9,10}$ Hypertension causes generalized vasospasm and increased peripheral vascular resistance further leading to increased afterload and reduced left ventricular ejection fraction. ${ }^{9,10}$ This leads to cardiac remodelling and increased left ventricular mass index. left ventricular ejection fraction (LVEF) in normal pregnancy is $55-70 \% .{ }^{11}$ Less than $50 \%$ is considered as decreased LVEF. Stroke Volume (SV) normally increases in pregnancy up till the end of the second trimester after which it decreases. Stroke Volume in normotensives is $73.3 \pm 14.19 \mathrm{ml}$, whereas it is $70.8 \pm 3.22$ $\mathrm{ml}$ in patients with hypertension. ${ }^{12}$ Left Ventricular mass (LV Mass) in normotensive is $90.6 \pm 19.8$ whereas it is $106 \pm 29.4$ in hypertensive pregnant women. ${ }^{13}$

Understanding the structure and function of the heart in hypertensive mothers is important in terms of timely diagnosis, better management and good prognosis. This study will discuss the importance and feasibility of echocardiography as a routine investigation tool in hypertensive disorders of pregnancy.

Aims and objectives of the study were to study the echocardiographic alterations in pregnant women with hypertension, to study the correlation between Echocardiographic abnormalities and outcome of pregnancy in patients of hypertensive disorders of pregnancy, to study the advantages of early diagnosis and early echocardiography in preventing adverse outcomes in patients of hypertensive disorders, and to analyse the fetomaternal outcome in hypertensive women with a normal echocardiographic finding compared to those with impaired echocardiographic findings.

\section{METHODS}

This is a retrospective study of 150 cases of hypertension in pregnancy conducted at the Obstetrics and Gynaecology department of a tertiary care centre in the year June 2019-July 2020. We have included patients suffering from chronic hypertension, gestational hypertension, pre-eclampsia. All OPD patients were screened out for hypertension. The patients who showed BP $>140 / 90 \mathrm{mmHg}$ on 2 occasions 4 hours apart were considered as hypertensive and as a routine protocol, they were admitted and all basic investigations and a departmental ECHO was done. In the patients who were detected in early pregnancy, repeat 2D ECHO was done near term.

Data was compared with terms of complications seen in hypertensive patients with structural and functional abnormal echocardiographic findings with those hypertensive patients in whom echocardiogram was normal. Changes in left ventricular ejection fraction, stroke volume and left ventricular mass in all the classes were studied. Cardiologist opinion was taken in patients showing abnormal echocardiographic findings and a decision regarding the mode of delivery was taken after consultation with the cardiologist.

\section{Inclusion criteria}

Pregnant women admitted in our institute in the year 2019-2020 suffering from gestational hypertension (BP $>140 / 90 \mathrm{mmHg}$ after 20 weeks of pregnancy and which normalizes after 3 months of postpartum). Preeclampsia (gestation hypertension + proteinuria $>300$ mgs in 24 hrs urine sample or dipstick proteinuria $>-+1$ or signs of end organ damage which include renal impairment, thrombocytopenia, epigastric pain, liver dysfunction, visual disturbances, headache). Chronic hypertension (BP> 140/90 before 20 weeks of pregnancy or which remains raised even after 3 months postpartum.

\section{Exclusion criteria}

Patients who came to our institute for the first time with eclampsia and required urgent management and in whom getting an Echocardiogram was not feasible. Women with previously known congenital cardiac conditions. Women who underwent abortion.

\section{Data analysis}

Comparison of fetomaternal outcome amongst patients with positive abnormal echocardiographic findings with those with a normal echocardiogram was done and comparison of outcome with the time of echocardiographic scan was performed using Chi Square test and Fisher Exact test using the ChiSquare calculator available on social science statistics website. Statistical significance was accepted at $95 \%$ confidence level $(\mathrm{p}<0.05)$. 


\section{RESULTS}

In this study, 150 pregnant female suffering from different forms of hypertensive disorders presented at our institute for routine antenatal checkup. Out of them, 12 (8\%) had chronic hypertension, $75(50 \%)$ had gestational hypertension, whereas $63(42 \%)$ had pre-eclampsia.

Table 1: Echocardiographic changes in hypertensive women.

\begin{tabular}{|c|c|c|c|c|c|c|}
\hline & \multicolumn{2}{|c|}{$\begin{array}{l}\text { LVEF } \\
\mathbf{N}=150(\% \text { of } \mathbf{N})\end{array}$} & \multicolumn{2}{|c|}{$\begin{array}{l}\text { Stroke volume } \\
N=150(\% \text { of } N)\end{array}$} & \multicolumn{2}{|c|}{$\begin{array}{l}\mathbf{L V} \text { mass } \\
\mathrm{N}=150(\% \text { of } \mathrm{N})\end{array}$} \\
\hline & Decrease & No change & Decrease & No change & Increase & No change \\
\hline Chronic hypertension & $2(1.34)$ & $10(6.67)$ & $10(6.67)$ & $2(1.33)$ & $3(2)$ & $9(6)$ \\
\hline Gestational hypertensior & $12(8)$ & $63(42)$ & $50(33.33)$ & $25(16.67)$ & $30(20)$ & $45(30)$ \\
\hline Pre eclampsia & $15(10)$ & $48(32)$ & $43(28.6)$ & $20(13.33)$ & $40(26.67)$ & $23(15.34)$ \\
\hline & $29(19.3)$ & $121(80.6)$ & $103(67.3)$ & $47(31.11)$ & $73(48.6)$ & $77(51.33)$ \\
\hline
\end{tabular}

Table 2: Incidence of structural Echocardiographic findings in patients suffering from hypertensive disorders in pregnancy.

\begin{tabular}{|lllll|}
\hline & $\begin{array}{l}\text { Chronic Hypertension } \\
\mathbf{N}=\mathbf{1 5 0}(\boldsymbol{\%} \text { of } \mathbf{N})\end{array}$ & $\begin{array}{l}\text { Gestational Hypertension } \\
\mathbf{N}=\mathbf{1 5 0}(\% \text { of } \mathbf{N})\end{array}$ & $\begin{array}{l}\text { Preeclampsia } \\
\mathbf{N}=\mathbf{1 5 0}(\% \text { of } \mathbf{N})\end{array}$ & $\begin{array}{c}\text { Total } \\
\mathbf{N}=\mathbf{1 5 0}(\% \text { of } \mathbf{N})\end{array}$ \\
\hline $\begin{array}{l}\text { No. of patient who had } \\
\text { structural anomalies in } \\
\text { Echocardiography }\end{array}$ & $5(3.3)$ & $15(10)$ & $12(8)$ & $32(21.3)$ \\
\hline
\end{tabular}

Table 3: Complications seen amongst hypertensive patients with structural abnormalities with those who had only functional abnormality and those who had a structurally and functionally normal cardiac condition.

\begin{tabular}{|c|c|c|c|c|}
\hline Complications & $\begin{array}{l}\text { Women with normal } \\
\text { structural and } \\
\text { functional heart } \\
\mathrm{N}=29(\mathrm{n}=\%)\end{array}$ & $\begin{array}{l}\text { Women with abnormal } \\
\text { structure and function of } \\
\text { heart } \\
\mathrm{N}=32(\mathrm{n}=\%)\end{array}$ & $\begin{array}{l}\text { Women with normal } \\
\text { structure and abnormal } \\
\text { function } \\
\mathrm{N}=89(\mathrm{n}=\%)\end{array}$ & $\begin{array}{l}\mathbf{p} \\
\text { value }\end{array}$ \\
\hline \multicolumn{5}{|c|}{ Maternal complications } \\
\hline $\mathrm{CCF}$ & $3(10.34)$ & $12(37.5)$ & $12(13.48)$ & $<0.05$ \\
\hline Atrial fibrillation & $1(3.34)$ & $5(15.62)$ & $1(1.12)$ & $<0.05$ \\
\hline Hypertensive crisis & $1(3.34)$ & $25(78.1)$ & $12(13.48)$ & $<0.05$ \\
\hline Cardiomyopathy & $1(3.34)$ & $6(18.7)$ & $1(1.12)$ & $<0.05$ \\
\hline ICU Admissions & $1(3.34)$ & $27(84.3)$ & $28(31.46)$ & $<0.05$ \\
\hline Maternal mortality & $1(3.34)$ & $5(15.62)$ & $1(1.12)$ & $<0.05$ \\
\hline \multicolumn{5}{|l|}{ Fetal complications } \\
\hline IUGR & $2(6.89)$ & $17(53.1)$ & $14(15.7)$ & $<0.05$ \\
\hline Preterm & $2(6.89)$ & $20(62.5)$ & $12(13.8)$ & $<0.05$ \\
\hline IUD & $1(3.34)$ & $6(18.7)$ & $5(5.61)$ & $<0.05$ \\
\hline
\end{tabular}

Amongst these classes, the changes in the echocardiographic variables were studied. LVEF $<55 \%$ is considered as decreased LVEF. Stroke volume $<73 \mathrm{ml}$ is considered as decreased stroke volume. Left ventricular mass index includes cases with both eccentric and concentric hypertrophy.

In order to see the severity of these findings, we have compared the complications seen amongst these 32 patients with those 89 who had only functional abnormalities without any anatomical structural defect and 29 hypertensive women who had a structurally and functionally normal heart. There were no patients found who had structural lesions without any functional abnormality.

Incidence of complications like CCF, atrial fibrillation and hypertensive crisis were more in those with structural lesions $(37.5 \%, 15.6 \%$, and $78 \%$ respectively) compared to the other 2 groups. Women with normal structural and functional Echocardiogram have least ICU admissions$3.34 \%$ only. We have compared the fetomaternal outcome with the time of scan. The outcome of patients who underwent their first echocardiographic scan in 1 st 
trimester were compared to those who underwent the scan in $2^{\text {nd }}$ and $3^{\text {rd }}$ trimesters. Out of the 150 women, 80 underwent echocardiography is $1^{\text {st }}$ trimester and 70 in the second and third trimester. We have compared the outcome of those who underwent their first scan in 1st trimester to those who underwent the first scan in later trimesters. $81 \%$ full term deliveries were seen in patients who underwent echocardiography in $1^{\text {st }}$ trimester.

Table 4: Comparison regarding outcome amongst patients who underwent Echocardiography in 1st trimester to those who underwent the procedure in $2^{\text {nd }}$ or $3^{\text {rd }}$ trimester.

\begin{tabular}{|c|c|c|c|}
\hline Outcome & $\begin{array}{l}\mathbf{1}^{\text {st }} \text { Trimester scan } \\
\mathbf{N}=\mathbf{8 0}(\mathrm{n}=\%)\end{array}$ & $\begin{array}{l}2^{\text {nd }} \text { and } 3^{\text {rd }} \text { Trimester scan } \\
N=70(n=\%)\end{array}$ & P value \\
\hline Maternal ICU admissions & $15(18.75)$ & $41(58.5)$ & $\mathrm{P}<0.05$ \\
\hline Full term deliveries & $65(81.2)$ & $39(55.7)$ & $\mathrm{P}<0.05$ \\
\hline Preterm deliveries & $12(15)$ & $22(31.4)$ & $\mathrm{P}<0.05$ \\
\hline IUD & $3(3.75)$ & $9(12.8)$ & $\mathrm{p}<0.05$ \\
\hline IUGR babies & $12(15)$ & $21(30)$ & $\mathrm{P}<0.05$ \\
\hline Live babies at 3 months postpartum & $72(90)$ & $52(64.28)$ & $\mathrm{P}<0.05$ \\
\hline
\end{tabular}

\section{DISCUSSION}

Hypertensive disorders in pregnancy are associated with high maternal mortality and morbidity. The study showed a decrease in LVEF and Stroke Volume with an increased left ventricular mass suggestive of diastolic dysfunction. These changes were more pronounced in pre-eclamptics compare to chronic hypertension. In our study, $19.3 \%$ of the 150 hypertensive women taken presented with decreased LVEF, 68.6\% had decreased stroke volume and $73 \%$ had increased LV mass. These findings were consistent with the study conducted by Kathryn et al, which showed decreased LVEF in 17 pre-eclamptics out of 57 patients. $^{14}$

Similarly decreased Stroke Volume (SV) is also seen in study of Rizwana et al who found average SV to be $70.8 \pm 3.22 \mathrm{ml}^{15}$ The study of Manuel et al showed $90 \%$ subjects to have SV $<70 \mathrm{ml}$ compared to our study where SV $<70 \mathrm{ml}$ was seen in $68.6 \%$ subjects. ${ }^{13}$ Our study demonstrated that $73 \%$ women had increased Left Ventricular mass in comparison to Manuel et al who showed $47.3 \%$ cases to present with left ventricular mass thickness in form of eccentric or concentric hypertrophy. ${ }^{13}$

The study showed poor feto-maternal outcome in patients with abnormal structural echocardiographic findings. Such women had an increased rate of deterioration and increased morbid events during pregnancy. Increased incidence of IUGR and fetal demise which was $53.1 \%$ and $18.7 \%$ respectively is attributed to the decreased uterine artery blood flow as a result of increased peripheral vascular resistance during pregnancy. In women with only deranged cardiac function, fetomaternal outcome was better in comparison to women with both structural and functional abormality. Those who have a normal echocardiographic report have best prognosis amongst the 3 classes.
Preeclampsia and cardio-vascular disorders also tend to share common risk factors like obesity, smoking, increased cholesterol levels, stress, sedentary lifestyle as well as some genetic factors. ${ }^{17}$ This is the reason that preeclampsia is more associated with abnormal functional echocardiographic changes. The present study has observed that early diagnosis of cardiac lesions and its appropriate management is associated with better pregnancy outcome, similarly observed by James et al study. James et al showed that $\mathrm{LV}$ remodelling was seen in $33 \%$ patients at 20- 23 weeks of pregnancy. ${ }^{5}$ Patients with increased LV mass are more likely to have complications. Time of scan is also important as abnormal placentation occurs by 20 weeks of pregnancy. Hence early Echocardiogram helps decrease the incidence of IUD and preterm deliveries due to IUGR and abnormal doppler.

Echocardiography can reveal cardiac impairment in gestational hypertension and preeclampsia, which changes antenatal management (medication, frequency of monitoring, and timing of delivery) and can indicate when postnatal follow-up is warranted. In our study, 27 out of the $32(84.3 \%$ ) subjects with abnormal structural Echocardiogram findings had poor outcome in terms of hypertensive crisis or CCF or ICU admissions. Out of the 89 with only functional impairment, rate of ICU admissions was $31.46 \%$. Total $62.5 \%$ out of the 32 with structural abnomalities and $13.8 \%$ out of the 89 with only functional abnormality had preterm deliveries. Incidence of such poor outcome was found to be less in the control group of 29 hypertensive women who had a normal heart structurally and functionally. Thus Echocardiogram if performed can identify the high risk patients who need better monitoring and can improve prognosis in such patients.

This study also showed that if the abnormal Echocardiographic findings were identified during early pregnancy and proper care was taken, prognosis 
improved and the rate of complications decreased. Early onset preeclampsia can have more changes especially near term and so a repeat Echocardiography should always be done in such cases when the patient reaches near term pregnancy.

Echocardiogram if done early in pregnancy can thus improve both the maternal and the fetal outcome. Cardiac MRI and trans-oesophageal Echocardiography are newer modalities. Cardiac MRI gives better soft tissue contrast without any ionizing radiation. ${ }^{18}$ Echocardiography has an interobserver varaiation of $10-15 \%$ which is overcomed by cardiac MRI. ${ }^{18}$

Also, the limitation by poor acoustic window can be overcomed by cardiac MRI. ${ }^{18}$

\section{CONCLUSION}

The cardiac structure and function are altered in pregnant women suffering from hypertensive disorders in different forms. Recognition of this impairment in cardiac function is important in management of gestational hypertension and pre-eclampsia and in improving the fetomaternal outcome. Early recognition and management can bring better prognosis. 2-dimensional echocardiography is an important non-invasive technique to understand the cardiac structure and function and should be done as early as possible in hypertensive women. The cardiac structure should be re-evaluated near term in patients who present with hypertension since early pregnancy. Combined Obstetrician and Cardiologist care results into good fetomaternal outcome.

\section{ACKNOWLEDGMENTS}

Authors would like to thank all respected teachers, faculty colleague, post graduate residents and hospital staff for their support.

Funding: No funding sources

Conflict of interest: None declared

Ethical approval: The study was approved by the Institutional Ethics Committee

\section{REFERENCES}

1. Sajith M, Nimbargi V, Modi A, Sumariya R, Pawar A. Incidence of Pregnancy induced Hypertension and prescription pattern of antihypertensive drugs in pregnancy. Int J Pharmacol Sci Res. 2014;5(4):16370.

2. Vigil-De Gracia P, Montufar-Rueda C, Ruiz J. Expectant management of severe preeclampsia and preeclampsia superimposed on chronic hypertension between 24 and 34 weeks' gestation. Eur J Obstet Gynecol Reprod Biol. 2003;107:24-7.

3. Say L, Chou D, Gemmil A, Tuncalp O, Moller AB, Daniell J, et al. Global causes of maternal death: a
WHO Systemic analysis Lancet Global Health. 204;2:e323-e333.

4. National High Blood Pressure Education Program, Working Group on High Blood Pressure.Report of the National High Blood Pressure Education Program in Pregnancy. Am J Obstet Gynecol. 2000;183:S1-S22.

5. Castleman JS, Ganapathy R, Taki F, Lip GY, Steeds RP, Kotecha D. Echocardiographic structure and function in hypertensive disorders of pregnancy: a systematic review. Circulation: Cardiovas Imaging. 2016;9(9):e004888.

6. Robson SC, Hunter S, Boys RJ, Dunlop W. Serial study of factors influencing changes in cardiac output during human pregnancy. Am J Physiol. 1989;256(4 pt 2):H1060-H1065.

7. Rubler S, Damani PM, Pinto ER. Cardiac size and performance during pregnancy estimated with echocardiography. Am J Cardiol. 1977;40:534-40.

8. Robson SC, Boys RJ, Hunter S. Doppler echocardiographic estimation of cardiac output: analysis of temporal variability. Eur Heart J. 1988;9:313-8.

9. Hunter S, Robson SC. Adaptation of maternal heart in Pregnancy. Br Heart J. 1992;68:540-3.

10. Poppas A, Shroff SG, Korcarz CE, Hibbard JU,Berger DS, Lindheimer MD, et el. Serial assessment of the cardiovascular system in normal pregnancy. Role of arterial compliance and pulsatile arterial load. Circulation. 1997;95:2407-15.

11. Zou C, Wu X, Zhou Q, Zhang Y, Lyu R, Zhang J. Frequency and predictors of recovery of normal left ventricular ejection fraction and end-diastolic diameter in patients with dilated cardiomyopathy. OCT. 2014;42(10):851-5.

12. Jain N, Verma A, Rajoria L. Evaluation of Echocardiographic Systolic Parameters in PreEclamptics and Normotensives Women. J Obstet Gynecol India. 2016;66(1):187-91.

13. Vázquez Blanco $M$, Grosso $\mathrm{O}$, Bellido $\mathrm{CA}$, Iaviécoli OR, Berensztein CS, Ruda Vega $\mathrm{H}$, et al. Left ventricular geometry in pregnancy-induced hypertension. American J Hypertension. AJH 2000;13:226-30.

14. Lindley KJ, Conner SN, Cahill AG, Novak E, Mann DL. Impact of preeclampsia on clinical and functional outcomes in women with peripartum cardiomyopathy. Circulation: Heart Failure. 2017;10(6):e003797.

15. Solanki R, Maitra N. Echocardiographic assessment of cardiovascular hemodynamics in preeclampsia. $\mathrm{J}$ Obstet Gynecol India. 2011;61(5):519-22.

16. Hameed A, Karaalp IS, Tummala PP, Wani OR, Canetti M, Akhter MW, et al. The effect of valvular heart disease on maternal and fetal outcome of pregnancy. ACC. 2001;37(3):893-9.

17. Wei J, Liu CX, Gong TT, Wu QJ, Wu L. Cigarette smoking during pregnancy and preeclampsia risk: a systematic review and meta-analysis of prospective studies. Onco Target. 2015;6:43667-78. 
18. Shah S, Chryssos ED, Parker H. Magnetic Resonance IMAGING: A Wealth of Cardiovascular Information. Oschner J. 2009;9(4):266-77
Cite this article as: Parikh PM, Goswami VM, Shah SR, Vyas RC, Damor H. Significance of 2 dimensional-echocardiography in hypertensive disorders of pregnancy: a study in tertiary care centre, Ahmedabad, Western India. Int J Reprod Contracept Obstet Gynecol 2021;10:279-84. 